\title{
Study of the Feasibility of "mix" of Species from Sawmill Waste and Limiting for Particleboard
}

\author{
Luciane Simal Alves ${ }^{1}$, Sérgio Augusto Mello da Silva ${ }^{1}$, Maximiliano dos Anjos Azambuja ${ }^{2}$, \\ Luciano Donizeti Varanda ${ }^{3}$, André Luis Christoforo ${ }^{4, *}$, Decio Gonçalves ${ }^{5}$, Francisco Antonio Rocco Lahr ${ }^{5}$ \\ ${ }^{1}$ Department of Civil Engineering, Paulista State University, Experimental Campus of Ilha Solteira, Ilha Solteira, 15385-000, Brazil \\ ${ }^{2}$ Department of Civil Engineering, Paulista State University, Experimental Campus of Bauru, Bauru, 17033-360, Brazil \\ ${ }^{3}$ Department of Science and Engineering Material, Engineering School of São Carlos (EESC/USP), São Carlos, 13566-590, Brazil \\ ${ }^{4}$ Department of Mechanical Engineering, Federal University of São João del-Rei, São João del-Rei, 36307-352, Brazil \\ ${ }^{5}$ Department of Structural Engineering, Engineering School of São Carlos (EESC/USP), São Carlos, 13566-590, Brazil
}

\begin{abstract}
This study aims to determine physical properties of particleboard made of sawmill waste, as a mix of several wood species, and two adhesives: urea-formaldehyde, usually employed in industry (even with drawbacks or formaldehyde emission during pressing) and FASTBOND ${ }^{\circledR}$, water based resin, still poorly referenced in literature. Sixteen panels have been produced, in four experimental conditions, defined by using two adhesives and a $12 \mathrm{~mm}$ thick limiter (or not). Variance analysis was adopted to evaluate influence of experimental conditions on physical properties of produced panels, manufactured in nominal dimensions $350 \times 350 \mathrm{~mm} ; 10 \%$ resin related to particles mass (at $5 \%$ moisture); $3.5 \mathrm{MPa}$ compaction pressure, temperature $130^{\circ} \mathrm{C}$, in a $10 \mathrm{~min}$ cycle. Tests to determine density, moisture content, swelling and water absorption were carried out based on normative parameters of ABNT NBR 14810:2006. Results have been satisfactory to panels produced with urea-formaldehyde but those manufactured with polychloroprene based resin (FASTBOND ${ }^{\circledR}$ ) not meet regulatory requirements. Best results have been obtained without limiter.
\end{abstract}

Keywords Particleboards, Wood waste, Physical properties, Analysis of variance

\section{Introduction}

From reconstitution of wood waste, to obtain new products is possible and desirable, as composites like MDP (medium density particleboards) in different configurations [1].

MDP are conceptualized by Bertonili et al[2]; Iwakiri[3]; Maloney[4] and Moslemi[5] as panels produced with wood particles, by incorporating synthetic resins or other adhesives, consolidated through a cycle pressing, applying constant temperature and pressure.

MDP properties can be improved depending on particles size, volume and type of adhesive, pressure intensity, time and pressing temperature, as well as possible introduction of additives during manufacturing process[6].

It is estimated that $4 \%$ of Brazilian MDP production are intended for building construction industry and applied as floors, walls, light structural components and others[7].

However, according to latest data from Brazilian Association Panels Industry[8], MDP applications are focused in furniture industry (tops tables, side cabinets and

* Corresponding author:

alchristoforo@yahoo.com.br (André Luis Christoforo)

Published online at http://journal.sapub.org/ijme

Copyright (C) 2014 Scientific \& Academic Publishing. All Rights Reserved so). Packaging industry is also a promising scenario, due to constant research projects aiming increasing properties that meet specific requirements[2].

The main factors driving MDP consumption are: search for alternatives to solid wood; possibility of obtaining products with low heterogeneity; technological modernizati on of industrial park; collaborative efforts with environment; and improvement in consumer income, which gave strong impetus to construction and furniture industries.[9]

In Brazil, forest-based industries generate an impressive amount of waste during operational phases, from logging until the final product[10]. According to Brito[11], lumber, veneer and plywood industries generate waste about $20.000 .000 \mathrm{~m}^{3} /$ year, in several shapes, representing more than $50 \%$ of original logs volume.

According to Feitosa[12], only $35 \%$ of each log are processed into sawn products and $65 \%$ are wasted. Carneiro [13] observed that wastage per trunk of wood processing industries is around $60 \%$. This author also reports that some companies even have wastage $80 \%$ per trunk, exacerbated value, considering the current environmental concerns and economic exploitation.

Iwakiri[10] asserts that a substantial part of waste from wood processing of wood is used to generate energy for industrial and domestic purposes. However, despite its social benefits, this usage aggregates very little value to final 
product, requiring alternative ways to use this waste. Utilization of waste from sawmills to produce MDP is an interesting option to lead higher added value products.

The author[10] also investigated feasibility of using Eucalyptus maculata, E. grandis and E. tereticornis residues to produce MDP, employing urea-formaldehyde resin. Test results indicated that the studied panels showed physical and mechanical properties equivalent to those with some benchmark species as Pinus elliottii, Mimosa scabrella and E. dunnii.

Urea-formaldehyde resin has wide application in wood based industry worldwide. In over $90 \%$ of wooden panels manufacturing, this resin is used because of its lower cost compared to other available adhesives[1].

According to Dias[14] urea-formaldehyde resin requires high temperatures (over $180^{\circ} \mathrm{C}$ ) to complete chemical reactions. Currently companies have been compressing at $200^{\circ} \mathrm{C}$, since they have been working with a low formaldehyde volatiles emission urea.

Lessmann[15] states that there has been an increasing action from environmentalists and users for low formaldehyde emission panels. This has aroused interest in urea-formaldehyde resins chemistry, while there have been technology searches and improvement of such resin.

Silva and Lahr[16] evaluated MDP production with homogeneous particles of low and medium density Amazonian species (Erisma uncinatum, Nectranda lanceolata and Erisma sp). Panels have been fabricated with a $10 \mathrm{~mm}$ thickness nominal; $0.75 \mathrm{~g} / \mathrm{cm}^{3}$ density nominal; $10 \%$ of castor-oil based bi-component polyurethane resin; particles $0.02 \mathrm{~mm}$ to $6 \mathrm{~mm}$ long; $90^{\circ} \mathrm{C}$ temperature; intensity pressure $4 \mathrm{MPa}$; 10 minute cycle. Evaluations, in accordance with code NBR14810: 2002, showed that Nectandra lanceolata panels meet code requirements.

Considering possibility of using sawmill residues materials and alternative resins, this study aims to evaluate feasibility of producing MDP in such conditions that code requirements to physical properties are obeyed.

\section{Material and Methods}

Particles obtained from waste of sawmills in São José do Rio Preto, northwest of São Paulo State, Brazil, were used. According to the suppliers, they came from wood species: Tauari (Couratari sp); Cupiúba (Goupia glabra); Garapa (Apuleia leiocarpa); Cambará ou Cedrinho (Erisma uncinatum).

Particle sizes, reduced using a knife mill (Figure 1a), resulted in a range from 2 to $6 \mathrm{~mm}$, as stated by $(17 ; 18 ; 19)$. Placed in a greenhouse, they reached approximately 5\% moisture content, required to bonding procedures.

Two adhesives were used: (a) urea formaldehyde resin $(\mathrm{pH}$ 7.8 to 8.2 ; solids content of $60 \%-66 \%$, based catalyst with ammonium sulfate) and (b) polychloroprene based resin (density from 1.07 to 1.11 g.cm-3 and $47-51 \%$ solids). Resin (a) was chosen because is the most employed in MDP industry; resin (b) was elected once studies about its performance aren't available in technical literature.

Resins were incorporated to particles using mechanical mixing for $10 \mathrm{~min}$ in a cylindrical drum.

Mixture was then placed in a mold, called forming mattresses (Figure 1b), followed by a pre-pressing (about $0.05 \mathrm{MPa}$ ) for initial particles cohesion. Subsequently, mold was removed and the material directed to a hydraulic press (Figure 1c) at a temperature of $130^{\circ} \mathrm{C}$ and $3.5 \mathrm{MPa}$ pressure, as recommended by $(20 ; 21)$. In this step, some panels were placed in metal thickness side limiters.

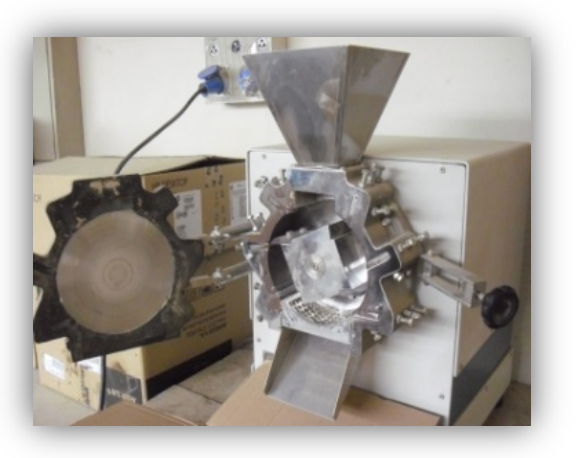

(a)

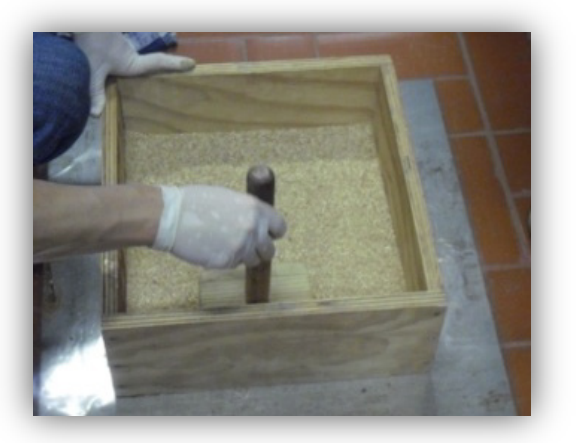

(b)

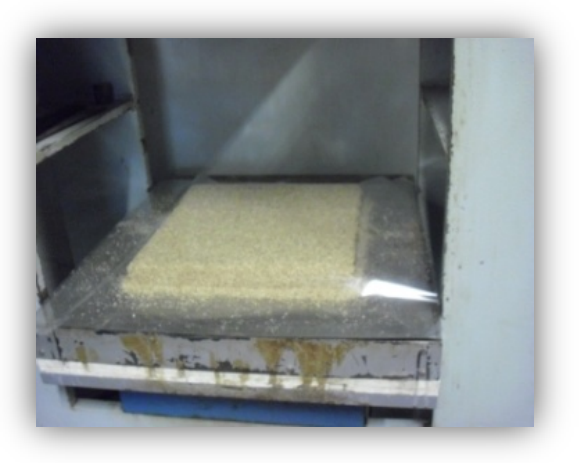

(c)

Figure 1. Knife Mill (a); Forming mattress (b); and hydraulic press (c)

Compression cycle consisted of a 3 min initial pressing, pressure relief for 30 seconds (for gases removal and, thereby, to minimize bubbles formation in panels) and $6 \mathrm{~min} 30 \mathrm{~s}$ of final pressure. Temperature and pressure at all stages of pressing were held constant.

This procedure was used for manufacturing the sixteen panels 16 , nominal density of $0.75 \mathrm{~g} . \mathrm{cm}^{-3}$, nominal 
dimensions $350 \times 350 \mathrm{~mm}, 10 \mathrm{~mm}$ thickness.

Parameters used for making plates and physical tests of density, moisture absorption and swelling, were established in ISO 14810:06[22].

Physical properties investigated were: density $(\rho)$; thickness swell in 2 (I-2h) and 24 hours (I-24h); water absorption in 2 (A-2h) and in 24 hours (A-24h); moisture content (TU), obtained according to the assumptions and calculation methods of ABNT NBR 14810:06[22].

For treatments were adopted as showed in Table 1.

Table 1. Treatments studied

\begin{tabular}{clc}
\hline Treatments & \multicolumn{1}{c}{ Type of adhesives } & Thickness limiters \\
\hline 1 & Urea formaldehyde (UF) & Without \\
2 & Urea formaldehyde(UF) & With \\
3 & Polychloroprene(FB) & With \\
\hline
\end{tabular}

Statistical analysis was performed as follow detailed.

ANOVA was evaluated at the 5\% significance level, consisting of the equivalence of means between treatments as null hypothesis $\left(\mathrm{H}_{0}\right)$ non-equivalence as the alternative hypothesis $\left(\mathrm{H}_{1}\right)$. P-value less than the significance level implies to reject $\mathrm{H}_{0}$ and accept it otherwise.

To validate the analysis of variance, Anderson-Darling test was applied to verify the normality of data distribution and F test, Bartlett's and Levene's test for assessment of homogeneity of variances among treatments. For both tests, significance level was set at 5\%. In Anderson-Darling test, null hypothesis was to assume normal distributions, non-normality as alternative hypothesis. P-value greater than significance level $\mathrm{H}_{0}$ involves accepting, rejecting it otherwise. For F tests, Bartlett and Levene null hypothesis assumed was the equivalence of variances between treatments, non-equivalence as alternative hypothesis. $\mathrm{P}$-value greater than significance level involves accepting $\mathrm{H}_{0}$, rejecting it otherwise. For the one-factor ANOVA and two levels (with and without the use of limiter), accused significance, the best response for treatment was evidenced by main effects plots, and ANOVA with three levels (treatments 1, 2 and 3), accused significance, the best response for treatment was evidenced by the contrast test of Tukey.

\section{Results and Discussions}

Tables 2 to 4 show the results of mean values $(\bar{x})$ and coefficients of variation $(\mathrm{CV})$ investigated the physical properties for each of three treatments adopted.

According to NBR 14810:06[22], medium density particleboard is classified in the range 0.551 to $0.750 \mathrm{~g} / \mathrm{cm}^{3}$. Results in this work panels with UF resin reached apparent densities averaged between 0.710 and $0.740 \mathrm{~g} / \mathrm{cm}^{3}$ (medium density) and those manufactured with $\mathrm{FB}$ resin presented mean density of $1.03 \mathrm{~g} / \mathrm{cm}^{3}$ (high density).

Mean results obtained in test after 2 hours of swelling in all samples were set up as a parameter $(8 \%)$ by NBR 14810:06[22]. However, it is noteworthy that normative parameters are related to industrial panels employing urea-formaldehyde resin and particles of pine and / or eucalyptus, with pressing temperatures over $150^{\circ} \mathrm{C}$.

Table 2. Physical properties of panels manufactured with UF resin without limiter (T1)

\begin{tabular}{ccc}
\hline Statistics & $\boldsymbol{\rho}\left(\mathbf{g} / \mathbf{c m}^{\mathbf{3}}\right)$ & TU (\%) \\
\hline $\bar{x}$ & 0.74 & 5.40 \\
$C v(\%)$ & 5 & 10 \\
\hline Statistics & $\mathbf{I - 2 h} \mathbf{( \% )}$ & $\mathbf{I - 2 4 h}(\%)$ \\
\hline $\bar{x}$ & 16.19 & 16.24 \\
$C v(\%)$ & 13 & 11 \\
\hline Statistics & $\mathbf{A - 2 h}(\%)$ & $\mathbf{A - 2 4 h}(\%)$ \\
\hline $\bar{x}$ & 68.27 & 64.19 \\
$C v(\%)$ & 6 & 8 \\
\hline
\end{tabular}

Table 3. Physical properties of panels manufactured with UF resin with the limiter (T2)

\begin{tabular}{ccc}
\hline Statistics & $\boldsymbol{\rho}\left(\mathbf{g} / \mathbf{c m}^{\mathbf{3}}\right)$ & TU (\%) \\
\hline $\bar{x}$ & 0.71 & 5.74 \\
$C v(\%)$ & 6 & 8 \\
\hline Statistics & $\mathbf{I - 2 h}(\%)$ & $\mathbf{I - 2 4 h}(\%)$ \\
\hline $\bar{x}$ & 18.29 & 20.27 \\
$C v(\%)$ & 10 & 10 \\
\hline Statistics & Statistics & $\mathbf{A - 2 4 h}(\%)$ \\
\hline $\bar{x}$ & 66.01 & 74.35 \\
$C v(\%)$ & 6 & 4 \\
\hline
\end{tabular}

Table 4. Physical properties of panels manufactured with FB resin without limiter (T3)

\begin{tabular}{ccc}
\hline Statistics & $\boldsymbol{\rho}\left(\mathbf{g} / \mathbf{c m}^{\mathbf{3}}\right)$ & TU (\%) \\
\hline $\bar{x}$ & 1.03 & 4.32 \\
$C \nu(\%)$ & 7 & 11 \\
\hline Statistics & $\mathbf{I - 2 h} \mathbf{( \% )}$ & $\mathbf{I - 2 4 h}(\%)$ \\
\hline $\bar{x}$ & 60.00 & 64.28 \\
$C \nu(\%)$ & 17 & 18 \\
\hline Estatísticas & $\mathbf{A - 2 h}(\%)$ & $\mathbf{A - 2 4 h}(\%)$ \\
\hline $\bar{x}$ & 83.15 & 90.81 \\
$C v(\%)$ & 13 & 11 \\
\hline
\end{tabular}

Values of swelling after 24 hours (I-24); water absorption $2 \mathrm{~h}(\mathrm{AA}-2 \mathrm{~h})$ and $24 \mathrm{~h}(\mathrm{AA}-24)$ respectively ranged from 16.24 to $64.28 \%$; from 66.01 to $83.15 \%$; and 64.19 to $90.81 \%$, respectively. NBR 14810:06[22] does not specify values for these tests. However, Iwakiri study[10] with waste from sawmills, the average swelling 24 hours, water absorption for $2 \mathrm{~h}$ and $24 \mathrm{~h}$ immersion in water, respectively, ranged from 23.51 to $38.81 \%$; from 13.94 to $41.74 \%$ and from 37.37 to $58.80 \%$. In research conducted by Iwakiri et al.[23], for panels of Pinus (Pinus sp), Bracatinga (Mimosa scabrella) and mixing these species, mean values were in the range from 23.87 to $53.41 \%$ for I-24; from 41.31 to $98.96 \%$ for AA-2h; and from 60.98 to $106.65 \%$ tor AA-24h. Therefore, behavior of panels produced in this study was compatible in comparison with these authors. 
It is believed that increasing the specific surface area of the particles due to the decrease of the particle crushing and use waste which contains different types of wood have been factors which influenced these results. The kind the adhesive may also have interfered in the cited parameters, once specimens with water-based adhesive resulted in nearly three times higher percentage. Press temperature can also influenced values.

Average moisture content obtained for panels made with UF resin was $5.57 \%$, within the range recommended by NBR 14810:06[22] of 5\% to $11 \%$. Panels with FB resin water presented $4.32 \%$ moisture content, therefore, slightly below the level indicated by the code.

Figures 2 and 3 show results of tests of normality and variance homogeneity, respectively. By P-values obtained for all responses were above significance level set, normality and homogeneity of variances among treatments were confirmed, validating ANOVA model.

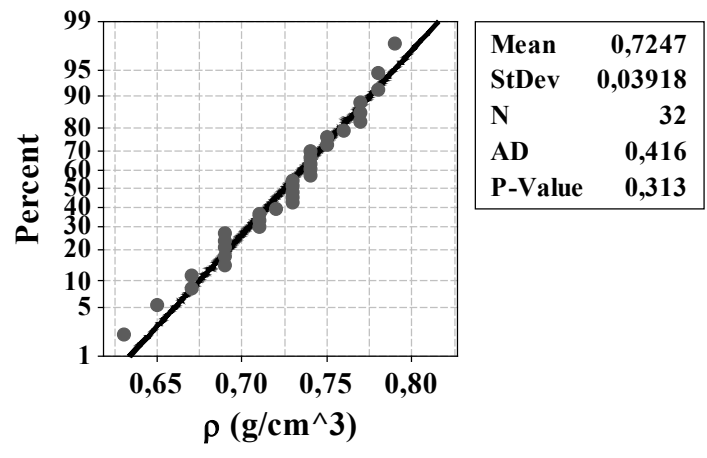

(a)
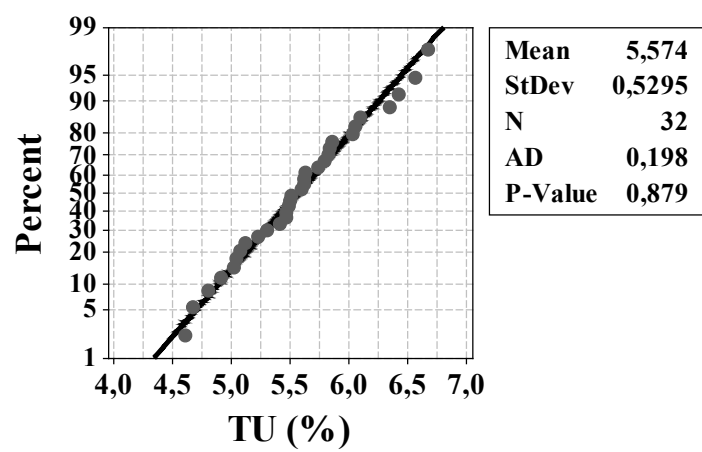

(b)
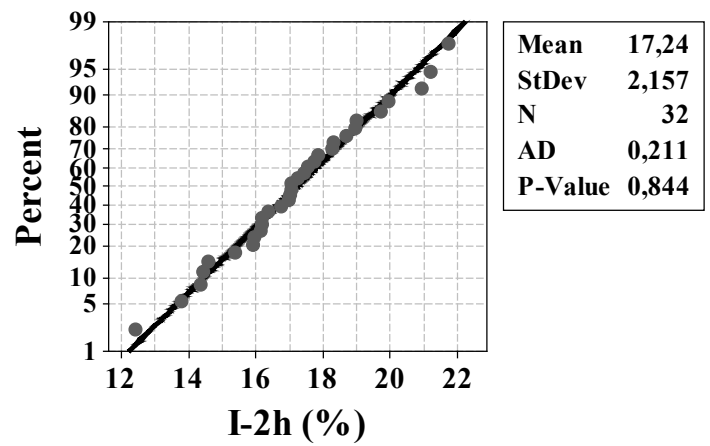

(c)

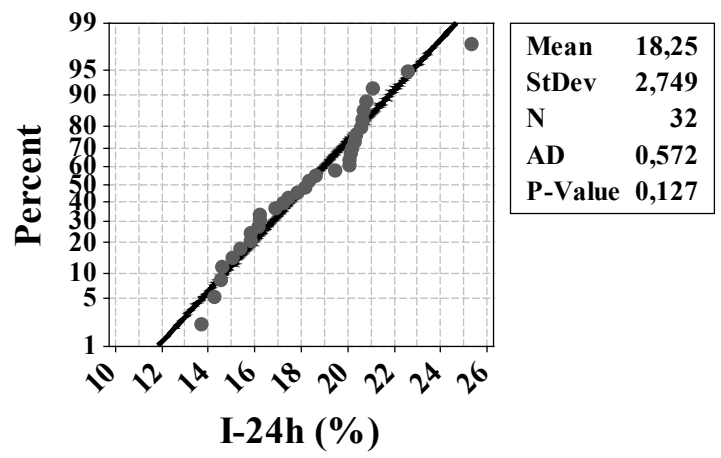

(d)

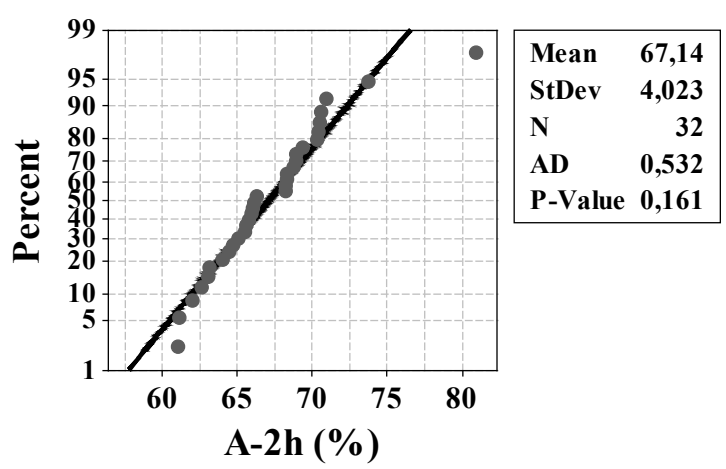

(e)

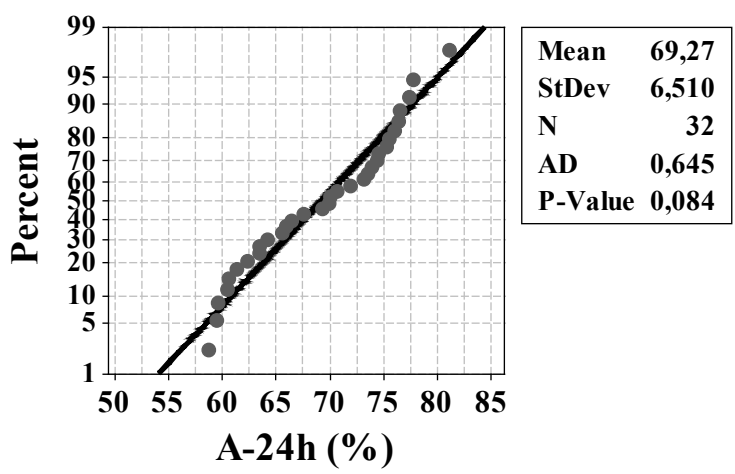

(f)

Figure 2. Results of normality test for physical properties
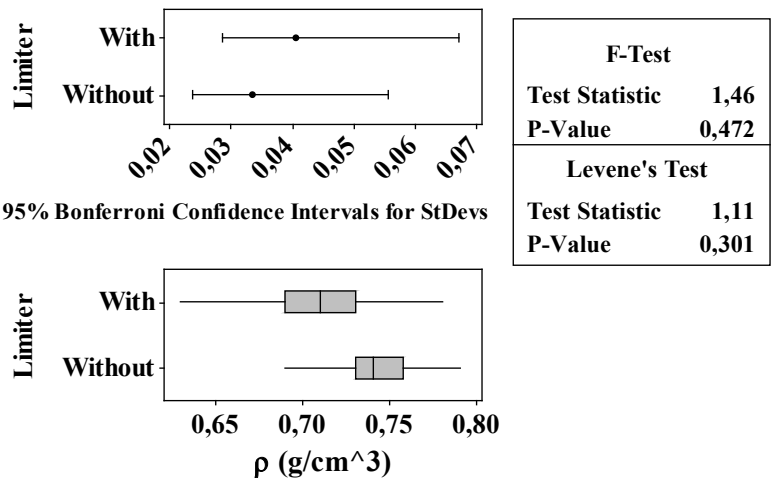

(a) 


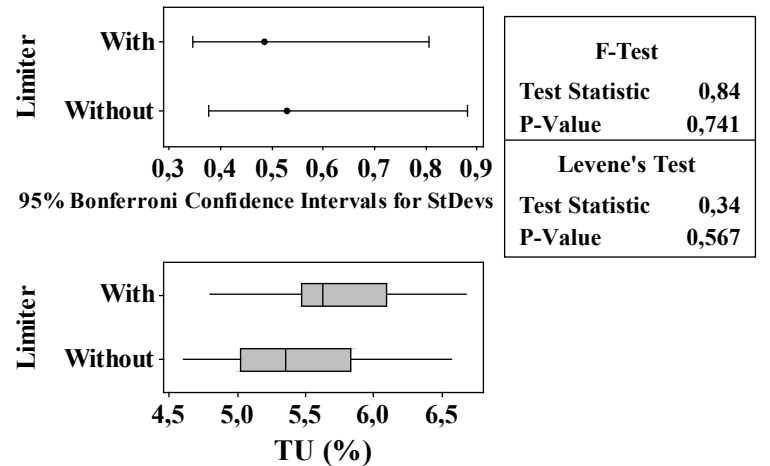

(b)
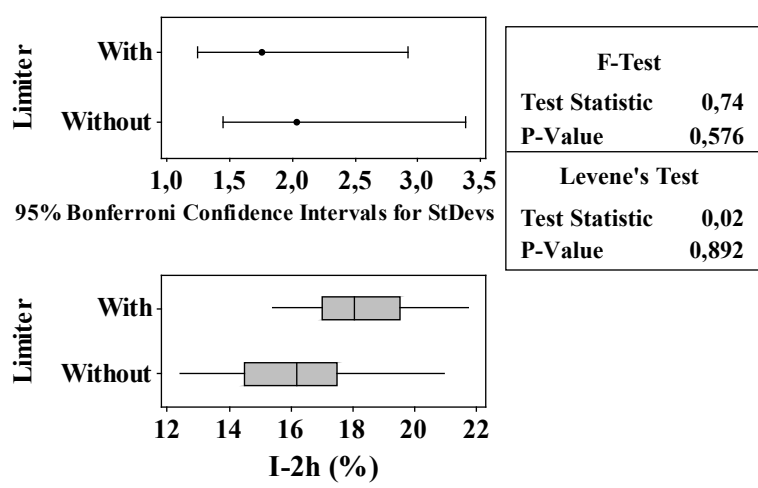

(c)
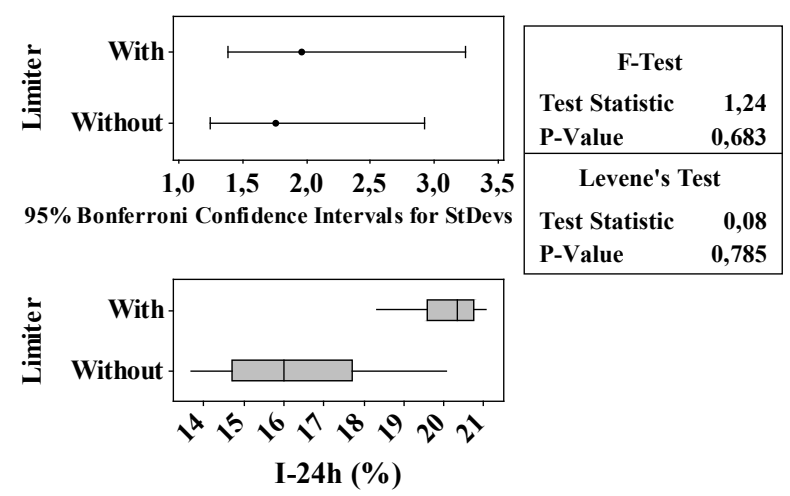

(d)

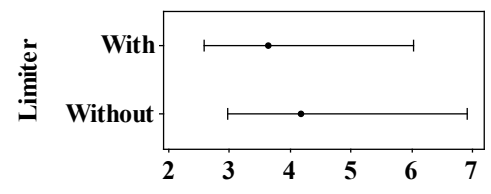

95\% Bonferroni Confidence Intervals for StDev

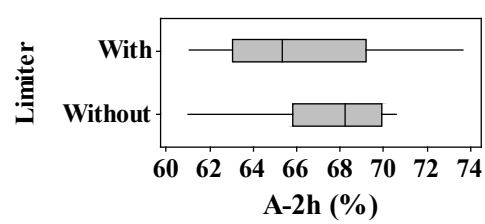

(e)

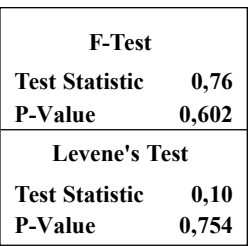

A-2h (\%)
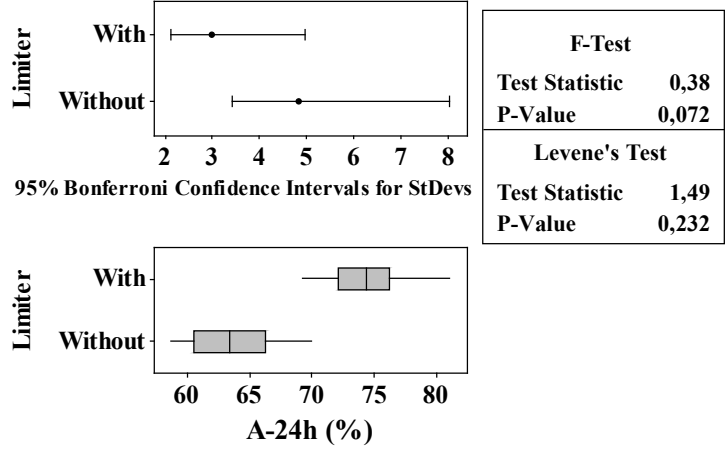

(f)

Figure 3. Results of tests for variances homogeneity for physical properties

Table 5 shows results of ANOVA concerning to the influence of using limiter in panels production (with or without) in physical properties of panels made with UF resin. Underlined P-values are considered significant. Note that GL denotes degrees of freedom of variance.

Table 5. Results of ANOVA: influence of using limiter

\begin{tabular}{ccc}
\hline Response & GL & P-valor \\
\hline P & 31 & 0,040 \\
TU & 31 & 0,070 \\
I-2h & 31 & 0,004 \\
I-24h & 31 & 0,000 \\
A-2h & 31 & 0,114 \\
A-24h & 31 & 0,000 \\
\hline
\end{tabular}

Figure 4 shows the graphs of main effects of ANOVA for responses significantly influenced by limiter inclusion.

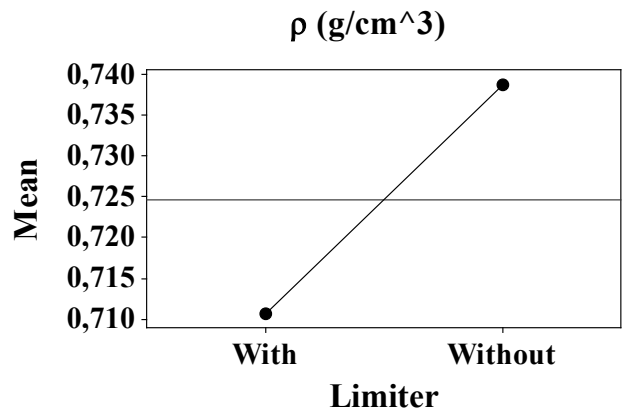

(a)

$$
\text { P-Value } \quad 0,754
$$

\section{I-2h (\%)}

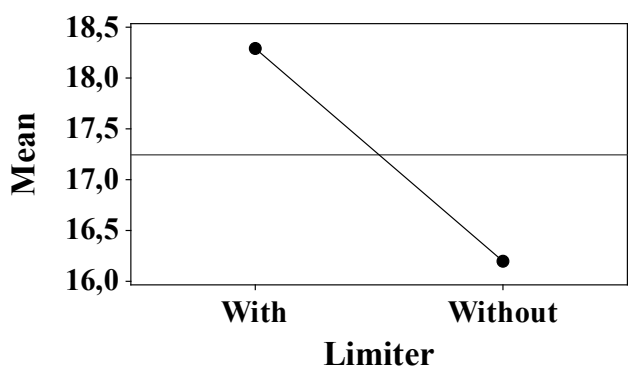

(b) 


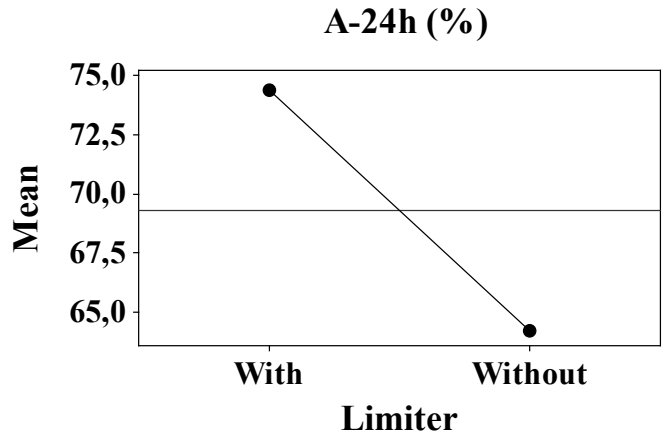

(c)

Figure 4. Graphics of ANOVA main effects for the factor: use of the limiter

Results in Table 5 show that the use of limiter is significant for density, thickness swelling after 2 hours and water absorption after 24 hours. Similar results (with or without coupling) were obtained for the three other physical properties of interest. Using limiter is responsible for increasing panels density (4\%) and decrease in thickness swelling in two hours and water absorption after 24 hours (12 and 14\%, respectively), when compared with the results of panels manufactured without limiter.

Table 6 shows results of ANOVA concerning to the influence on the physical properties of the boards manufactured by the choice of treatment with the test results of normality and homogeneity of variance. As seen in Table 5 , the P-values are considered significant by analysis of variance in Table 6 are also underlined. By P-values obtained for all responses were above the significance level set, is found the data normality and homogeneity of variances among treatments, validating the model ANOVA.

Table 6. Results of ANOVA: influence of using limiter

\begin{tabular}{ccccc}
\cline { 2 - 5 } & $\begin{array}{c}\text { P-valor } \\
\text { (A.-Darling) }\end{array}$ & $\begin{array}{c}\text { P-valor } \\
\text { (Bartlett) }\end{array}$ & GL & P-valor \\
\hline$\rho$ & 0,178 & 0,083 & 47 & 0,000 \\
$\mathrm{TU}$ & 0,601 & 0,860 & 47 & 0,000 \\
$\mathrm{I}-2 \mathrm{~h}$ & 0,093 & 0,078 & 47 & 0,000 \\
$\mathrm{I}-24 \mathrm{~h}$ & 0,236 & 0,372 & 47 & 0,000 \\
$\mathrm{~A}-2 \mathrm{~h}$ & 0,156 & 0,249 & 47 & 0,000 \\
$\mathrm{~A}-24 \mathrm{~h}$ & 0,328 & 0,592 & 47 & 0,000 \\
\hline
\end{tabular}

Table 7. Results of Tukey test for the best treatment response

\begin{tabular}{cccc} 
& \multicolumn{3}{c}{ Groupings } \\
\hline Treatments & T1 & T2 & T3 \\
\hline$\rho$ & B & B & A \\
TU & A & A & B \\
I-2h & B & B & A \\
I-24h & B & B & A \\
A-2h & B & B & A \\
A-24h & C & B & A \\
\hline
\end{tabular}

Table 7 presents results of Tukey test for the physical properties considered significant by ANOVA. Equal letters implies in treatment with equivalent averages.

Panels showed different behaviors. Highest values of density and lower values of moisture content were obtained to panels produced with FB resin (T3). For thickness swelling (after 2 and $24 \mathrm{~h}$ ) and water absorption (after $2 \mathrm{~h}$ ), the lowest values were derived from panels made with UF resin (T1 or T2). Water absorption (after $24 \mathrm{~h}$ ) to panels made with UF resin without limiter (T1) showed the best results.

Figures 4 and 5 illustrate results of the regression models to thickness swelling (after $24 \mathrm{~h}$ ) and water absorption (after $24 \mathrm{~h}$ ) versus density, respectively.

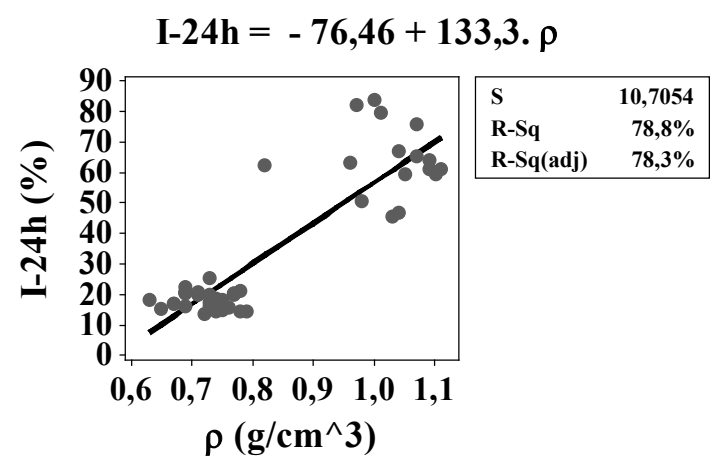

(a)

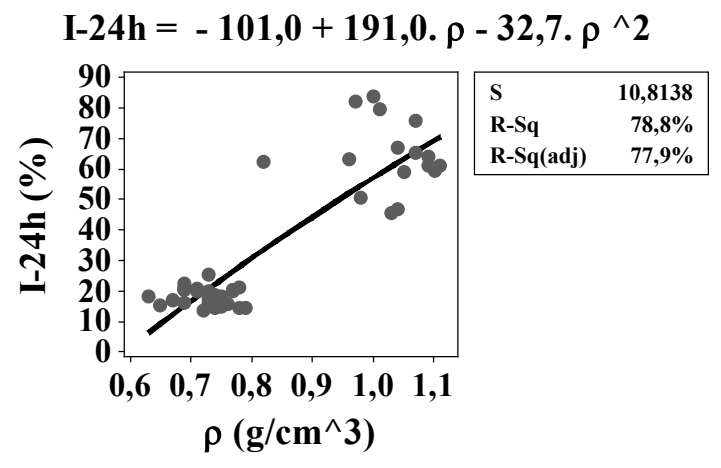

(b)

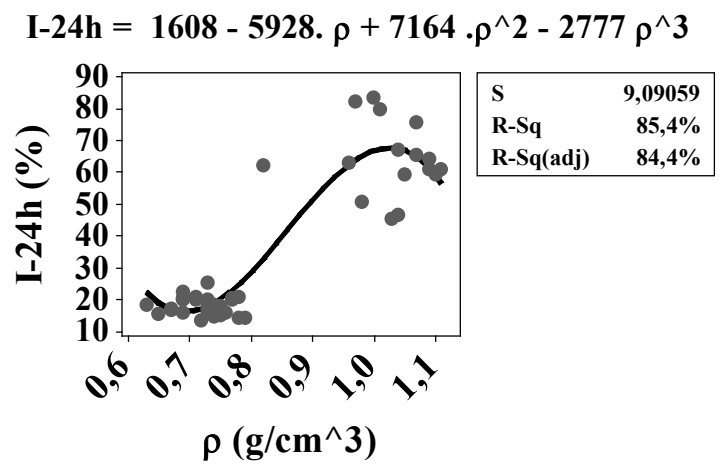

(c)

Figure 4. Results of linear regression models (a), square (b) and cubic (c) to thickness swelling (after $24 \mathrm{~h}$ ) versus density 


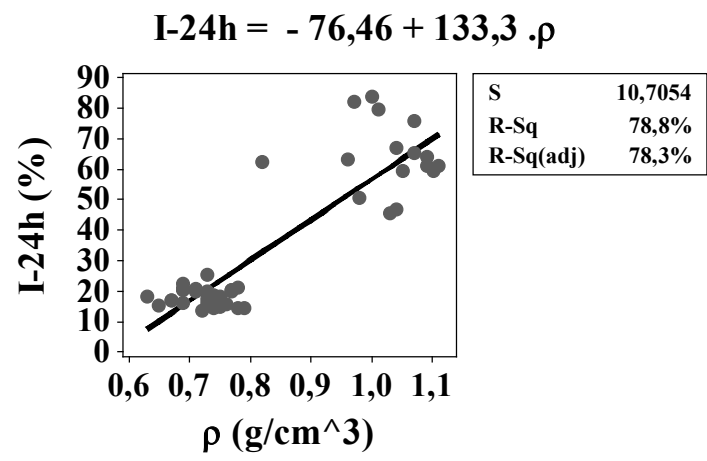

(a)

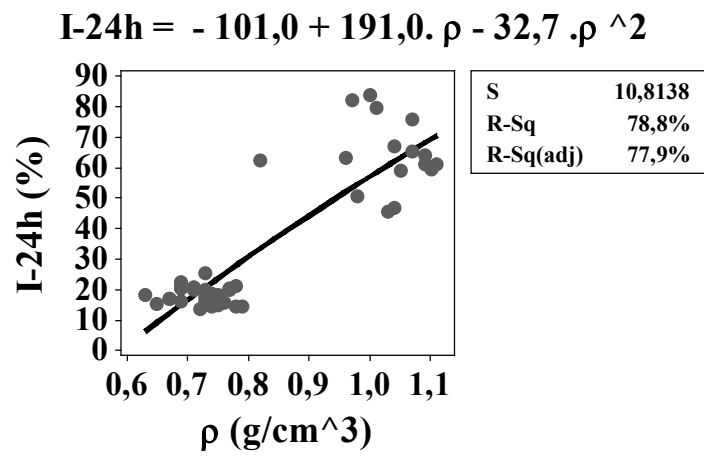

(b)

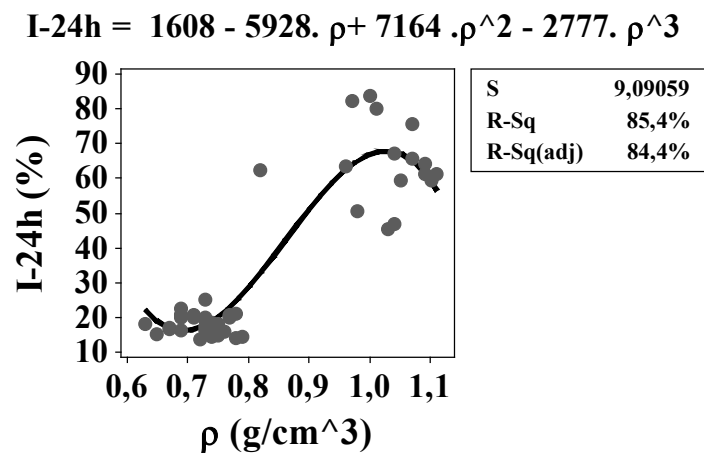

(c)

Figure 5. Results of linear regression models (a), square (b) and cubic (c) to water absorption (after $24 \mathrm{~h}$ ) versus density

The adjusted coefficients of determination $\left(\mathrm{R}^{2}\right.$ adj) for both relations and for the three regression models investigated were all above $70 \%$, resulting in good approximations. Among the adjustments considered, the polynomial of degree three presented the best results because its highest values of $\mathrm{R}^{2} \mathrm{Adj}$, with the smallest coefficient of variation of ANOVA regression model[18.26\%]. This turns possible to estimate swelling and water absorption(after 24h) of the boards manufactured with knowledge of the density by means of equation showed in Figures 4th and 5th, respectively.

\section{Conclusions}

Variables studied in this work, as the "mix" of wood species, use (or not) of thickness limiter, particles processing in a knife mill, pressing temperatures, may have been factors that influenced the changed values in relation to the codes recommendations adopted.

Treatment 1 (UF resin without limiter thickness) showed the best results in the parameters analyzed in this study, while non-use of the limiter is more favorable to the panel.

By means of statistical work, it was found that it is possible to estimate efficiently swelling and water absorption after 24 hours of the boards manufactured by means of polynomials of degree three, requiring only the density value.

In general, particleboards evaluated in this paper serve as base parameters to investigate, in further researches, how improving characteristics of products like those here analyzed.

\section{REFERENCES}

[1] Iwakiri, S. Reconstituted wood panels. Curitiba: FUPEF, Vol unique third edition, p. 3-5, 2005.

[2] Bertolini, M. of S., Rocco, F. A. L.; Agnelli, J. A. M., Artificial aging accelerated particle boards produced with waste treated Pinus sp CCB and castor oil based resin, 2012.

[3] Iwakiri, S., et al. Production of chipboard panels with high densification different types of resin. Scientia Forestalis. n. 68 p39-43, Aug 2005.

[4] Maloney, T.M. Modern particleboard and dry-process fiberboard manufacturing. 2.ed. San Francisco: Miller Freeman, 1993. 684p.

[5] Mosmeli, A.A. Particleboard: materials. London: Southem University Press, 1974. v.1, 244p.

[6] Isaia, G., C. (Ed.), Materials of construction and principles of materials science and engineering, 2. Ed São Paulo, Ibracon, 2010. 2 v.

[7] Brazilian Association of the Wood Panels - ABIPA 2009. Scenario Industry Panels. 8th Meeting Chair Productive Wood and Furniture. 2009. Available at: $<$ http://www.cgimo veis.com.br/mercado/documento.2009-11-06.3011537550/>. Accessed on: July 7, 2013.

[8] Association of the Manufacturers of Wood Panels - ABIPA (2012). Available at: <http://www.abipa.org.br/numeros.php >. Accessed on: August 11, 2012.

[9] Mattos, R. L. G., Gonçalves, R. M.; Chagas, F. B. Wood paneling in Brazil: Overview and perspectives. Sector BNDES, Rio de Janeiro, n. 27, p. 121-156, March 2008.

[10] Iwakiri, S., Cunha, A., B., Albuquerque, C., E., C.; Gorniak, E., Mendes, L. M. Waste from sawmills in the production of plywood panels of eucalyptus. Scientia Agriculture, v.1, n.1-2, p. 23-28, 2000. Publisher UFPR.

[11] Brito, E. O. Estimation of waste production in the Brazilian sawmill and wood lamination. Wood Magazine, Caxias do Sul, v.26, p.34-39, 1996.

[12] Feitosa, B. C. Utilization of wood waste in Para 2008. 
Available at: $<$ http://www.remade.com.br/pt/revista_materia. php?edicao=114\&id=12741 $>$. Accessed: 10/11/2013.

[13] Carneiro, M., S., Production process waste in five timber in the municipality of Paragominas-PA. 2006. 65 p. Completion of course work submitted for the undergraduate course of Agroindustrial Technology, University of the State of Pará, Paragominas.

[14] Dias, F. M. Application of polyurethane resin based on castor oil in the manufacture of chipboard panels. Wood products: summary of the work developed in the Laboratory of Wood and Timber Structures, SET-EESC-USP. San Carlos: School of Engineering of São Carlos, University of São Paulo, 2008, p. 73-92.

[15] Lessmann, V., E. Study curing reaction of urea-formaldehyde resins by nuclear resonance spectroscopy. Master's thesis. Graduate Program in Chemistry, Federal University of Paraná, UFP. Curitiba, 2008.

[16] S. Silva, F. The Rocco Lahr, "Plates of particles made of tropical wood waste with low density." Book: Recycling waste for building. Publisher University WSCF. Chapter 14, p. 343-365. Belo Horizonte (MG), 2007.

[17] Silva, S. A. M.; Christoforo, A. L.; Filho, S. L. M. R.; Varanda, L. D.; Lahr, F. A. R., Particleboard Manufactured with Bicomponent Polyurethane Resin Base on Castor Oil. International Journal of Composite Materials, 2 (6): 115-118, 2012.
[18] Dias, M. F.; Nascimento, M. F.; Espinosa M. M.; Lahr F. A. R.; Valarelli, I. D., Relation between the Compaction Rate and Physical and Mechanical Properties of Particleboards. Material Research, vol. 8, 2005.

[19] Poleto, S. F. S.; Varanda, L. D.; Nascimento, M. F.; Chistoforo, A. L.; Lahr, F. A. R., Evaluation of the Mechanical Properties of Particleboards Manufactured with Waste of Pinuselliottii Tree Pruning. Intenational Journal of Composite Materials, 3(3): 56-60, 2013.

[20] Silva, S. A. M.; Christoforo, A. L.; Panzera, T.H.; Almeida, D. H.; Segantini, A. A. S. S.; Lahr, F. A. R., Painéis de partículas de madeira leucena e resina poliuretana derivada de óleo de mamona. Ciência Rural, Santa Maria, v.43,n.8,p.1399-1404, ago,2013.

[21] Paes, J. B.; Nunes, S. T.; Lahr, F.A.R.; Nascimento, M.F.; Lacerda, R.M.A., Qualidade de chapas de partículas de Pinus elliottii coladas com resina poliuretana sob diferentes combinações de pressão e temperatura. Ciência Florestal, Santa Maria, v.21,n.3,p.551-558,jul.-set., 2011.

[22] Brazilian Association of Technical Standards - ABNT NBR 14810: plywood plates - Part 2: Requirements; - Part 3: Methods. Rio de Janeiro, 2006.

[23] Iwakiri, S.; Lotorraca, J. V. F., Silva, D. A.; Gabardo, J. L.; Klitzke, R. J.; Fofano Junior, A.; Fabrowski, F.; Interamense, M. T. Platemaking particle chipboard Pinus elliottii (Engelm) and Eucalyptus dunnii (Maid). Journal of Agricultural Sciences Sector, Curitiba, v.15, n.1, p.33-41, 1996. 